\title{
KINERJA PENYULUH PERTANIAN DALAM PELAKSANAAN PROGRAM KOMANDO STRATEGIS PEMBANGUNAN PERTANIAN (KOSTRATANI) DI KABUPATEN SRAGEN
}

\author{
Tika Sekar Kinasih, Widiyanto, Suminah \\ Fakultas Pertanian, Universitas Sebelas Maret, Jl. Ir. Sutami 36A, Surakarta, Indonesia
}

Koresponden Email: tikasekarkinasih80@gmail.com

\begin{abstract}
Abstrak
Program Kostratani merupakan salah satu kegiatan pembangunan pertanian yang ada di tingkat kecamatan dengan mengoptimalkan tugas, fungsi, dan peran Balai Penyuluhan Pertanian (BPP), sehingga penyuluh pertanian berperan aktif dalam keberhasilan program ini. Penelitian ini bertujuan untuk menganalisis kinerja penyuluh pertanian dan faktor-faktor yang mempengaruhi kinerja penyuluh pertanian dalam pelaksanaan program Kostratani di Kabupaten Sragen. Populasi dari penelitian ini adalah seluruh penyuluh pertanian di Kabupaten Sragen yang merupakan pegawai negeri yaitu sebanyak 54 orang, sehingga penentuan responden penelitian ini dilakukan dengan metode sensus, yaitu seluruh populasi digunakan sebagai sampel. Penelitian ini menggunakan metode kuantitatif dengan teknik survei. Teknik pengambilan data pada penelitian menggunakan wawancara melalui google form, observasi, studi pustaka, dan dokumentasi. Instrumen pada penelitian ini terdiri atas variabel $\mathrm{X}$ (faktor-faktor yang mempengaruhi kinerja) yaitu umur, frekuensi pelatihan kerja, masa kerja, jumlah kelompok tani, serta ketersediaan sarana dan prasarana, sedangan variabel Y (kinerja penyuluh pertanian), yaitu terdiri atas tahap persiapan, pelaksanaan serta evaluasi dan pelaporan. Analisis data yang dilakukan adalah dengan menggunakan analisis deskriptif dan uji regresi linear berganda. Hasil dari analisis menunjukkan bahwa kinerja penyuluh pertanian di Kabupaten Sragen dalam pelaksanaan program Kostratani berada pada kategori cukup baik. Faktor-faktor berpengaruh secara signifikan terhadap kinerja penyuluh pertanian di Kabupaten Sragen sebesar $19,5 \%$ pada tingkat signifikansi $\alpha=5 \%$. Faktor yang berpengaruh signifikan terhadap kinerja yaitu frekuensi pelatihan kerja, sedangkan faktor-faktor yang tidak berpengaruh signifikan terhadap kinerja yaitu umur, masa kerja, jumlah kelompok tani binaan serta ketersediaan sarana dan prasarana.
\end{abstract}

\section{Kata Kunci: kinerja, Kostratani, penyuluhan pertanian}

\begin{abstract}
The Kostratani Program is one of the agricultural development activities at the sub-district level by optimizing the duties, functions and roles of the Agricultural Extension Center (BPP), so that agricultural extension workers play an active role in the success of this program. This study aims to analyze the performance of agricultural instructors and the factors that influence the performance of agricultural instructors in implementing the Kostratani program in Sragen Regency. The population of this research is all agricultural extension workers in Sragen Regency who are civil servants as many as 54 people, the determination of the respondents in this study was carried out by the census method, namely the entire population was used as a sample. This study uses quantitative methods with survey techniques. Data collection techniques in the study used interviews via google form, observation, literature study and documentation. The instrument in this study consisted of variable X (factors that affect performance) namely age, frequency of job training, years of service, number of farmer groups and the availability of facilities and infrastructure, while variable $Y$ (performance of agricultural extension workers) consisted of the preparation, reportation and implementation stages. and evaluation and reporting. The result of the analysis shows that the performance of agricultural extension in Sragen Regency for implementation Kostratani program is in the good enough category. The factors have a significant affect on the performance of agricultural extension in Sragen Regency by 19,5\% at the level of significance $\alpha=5 \%$. Factor that have a significamt effect on performance is the frequency of traning, while the factors than do not have a significant effect on performnace are age, years of service, number of fostered farmer group and availability of infrastructure.
\end{abstract}

Keywords: performance, Kostratani, agricultural extension 


\begin{tabular}{lll} 
Info Artikel & Received & $: 13$ November 2021 \\
& Revised & $: 27$ Desember 2021 \\
& Accepted & $: 28$ Desember 2021 \\
\hline
\end{tabular}

\section{PENDAHULUAN}

Data kependudukan nasional Indonesia dirilis oleh Direktorat Jenderal Kependudukan dan Pencatatan Sipil (Dukcapil) pada semester I tahun 2020, yaitu sebesar 268.583.016 jiwa. Jumlah penduduk Indonesia mengalami kenaikan sebesar $0,77 \%$ pada tahun ini. Tingginya laju pertumbuhan penduduk di Indonesia menunjukkan bahwa setiap tahunnya terjadi peningkatan pada populasi penduduk yang berpengaruh terhadap jumlah pemenuhan kebutuhan pangan nasional.

Tingginya laju pertumbuhan penduduk di Indonesia menunjukkan bahwa setiap tahunnya terjadi peningkatan pada populasi penduduk yang berpengaruh terhadap jumlah pemenuhan kebutuhan pangan nasional. Peningkatan jumlah penduduk Indonesia diikuti dengan meningkatnya kebutuhan pemenuhan pangan penduduk Indonesia karena pangan sendiri merupakan kebutuhan primer yang harus terpenuhi. Berdasarkan data BPS (2010), diprediksi jumlah penduduk Indonesia menjadi 350 juta pada tahun 2030, maka kebutuhan beras penduduk meningkat mencapai angka 90-100 juta ton per tahun. Pertumbuhan penduduk ini perlu diiringi dengan peningkatan produktivitas pangan agar kebutuhan pangan seluruh penduduk Indonesia dapat terpenuhi secara kuantitas dan kualitas.

Berdasarkan data Badan Pusat Statistika (BPS) tahun 2019 Kabupaten Sragen memiliki jumlah penduduk yaitu 890.158 jiwa. Kabupaten Sragen memiliki luas wilayah sebesar 941,55 $\mathrm{km}^{2}$ dengan pembagian wilayah terdiri atas 20 kecamatan. Banyaknya penduduk membuat pemenuhan kebutuhan pangan semakin meningkat. Perlu diperhatikan ketahanan pangan pada tiap daerah secara cepat agar pemerintah bisa memberikan solusi untuk mengoptimalkan hasil produktivitas pertanian.

Salah satu program yang dilaksanakan oleh Dinas Pertanian dan Ketahanan Pangan Kabupaten Sragen adalah Komando Strategis Pembangunan Pertanian (Kostratani). Programini dapat dijadikan sebagai salah satu jalan keluar untuk membangun pertanian di Indonesia yang telah ditetapkan melalui Peraturan Menteri Pertanian No 49 Tahun 2019. Kostratani yang merupakan pusat kegiatan pembangunan pertanian untuk optimalisasi peran dan fungsi Balai Penyuluhan Pertanian (BPP) dengan memanfaatkan teknologi informasi. Pembangunan pertanian dapat
Jurnal Agrica Ekstensia

Vol. 15 No. 2 Tahun 2021

p-ISSN $\quad$ : 1978-5054

e-ISSN dilakukan dengan dukungan dari SDM pertanian yang profesional, mandiri, berdaya saing, dan juga modern.

Program Komando Strategis Pembangunan Pertanian (Kostratani) ini sangat memerlukan dukungan dari penyuluh pertanian yang ada di Kabupaten Sragen. Adanya program Kostratani, kinerja BPP semakin penting dan strategis dalam mewujudkan keberhasilan dan keberlanjutan pembangunan [1]. Penyuluhan oleh penyuluh pertanian merupakan pendidikan non formal kepada individu atau kelompok masyarakat yang dilakukan secara sistematik, terencana, dan terarah dalam usaha untuk mengubah perilaku secara berkelanjutan demi terjadinya peningkatan swadaya masyarakat. Program Kostratani sebagai kegiatan pembangunan pertanian yang mengoptimalisasi peran dan fungsi BPP dengan memanfaatkan teknologi memerlukan penyuluh dengan kompetensi yang baik.

Kinerja penyuluh pertanian di Kabupaten Sragen dalam program ini sangat diperlukan untuk mengoptimalkan keberhasilan dari program. Penyuluh sebagai ujung tombak pembangunan pertanian di Indonesia karena penyuluh berinteraksi langsung dengan petani, sehingga program pertanian dapat disalurkan langsung kepada petani [2]. Kinerja penyuluh pertanian ini terlihat pada persiapan, pelaksanaan, evaluasi, dan pelaporan program.

\section{Desain Penelitian}

\section{MATERIAL DAN METODE}

Metode dasar dalam penelitian ini menggunakan metode penelitian kuantitatif dengan teknik survei. Metode kuantitatif memandang dunia sebagai kenyataan yang dapat ditentukan secara objektif, sehingga panduan yang ketat dalam proses pengumpulan dan analisis data sangat penting [3]. Teknik survei dimaksudkan untuk melakukan penjajakan (eksploratif) dan deskriptif atau penjelasan mengenai hubungan hipotesis dengan indikator penelitian.

\section{Lokasi Penelitian}

Penelitian ini dilakukan di Kabupaten Sragen. Penentuan lokasi penelitian ini dilakukan secara sengaja (purposive) berdasarkan pertimbangan-pertimbangan tertentu sesuai dengan tujuan penelitian [4]. Pemilhan lokasi tersebut didasarkan atas 


\begin{tabular}{lll} 
Info Artikel & Received & $: 13$ November 2021 \\
& Revised & $: 27$ Desember 2021 \\
& Accepted & $: 28$ Desember 2021 \\
\hline
\end{tabular}

pertimbangan bahwa Kabupaten Sragen merupakan salah satu daerah yang telah melaksanakan program Kostratani dan beberapa wilayahnya mendapat bantuan dari pemerintah.

\section{Populasi dan Sampel}

Populasi ialah wilayah generalisasi yang terdiri dari obyek/subyek yang memiliki kuantitas dan karakteristik tertentu [5]. Populasi dalam penelitian ini adalah semua penyuluh pertanian PNS yang ada di Kabupaten Sragen yang berjumlah 54 orang. Penyuluh pertanian tersebut tersebar di 21 wilayah kerja yaitu 20 wilayah kecamatan dan satu wilayah administrasi kabupaten. Rincian wilayah kerja dan jumlah penyuluh dapat dilihat pada Tabel 1.

Tabel 1. Populasi Penelitian di Kabupaten Sragen

\begin{tabular}{clc}
\hline No & \multicolumn{1}{c}{ Wilayah } & $\begin{array}{c}\text { Jumlah Penyuluh } \\
\text { PNS }\end{array}$ \\
\hline 1 & Jenar & 1 \\
2 & Plupuh & 2 \\
3 & Gondang & 1 \\
4 & Mondokan & 1 \\
5 & Miri & 2 \\
6 & Ngrampal & 3 \\
7 & Masaran & 4 \\
8 & Sukodono & 3 \\
9 & Tangen & 2 \\
10 & Sambirejo & 2 \\
11 & Sidoharjo & 2 \\
12 & Sambung Macan & 3 \\
13 & Tanon & 3 \\
14 & Kalijambe & 2 \\
15 & Kedawung & 2 \\
16 & Sragen & 3 \\
17 & Sumberlawang & 2 \\
18 & Gesi & 2 \\
19 & Karangmalang & 2 \\
20 & Gemolong & 4 \\
21 & Dinas Kabupaten & \\
& Jumlah & 54 \\
\hline
\end{tabular}

Sumber : Data Sekunder 2021

Teknik pengambilan sampel harus dilakukan dengan tepat dan dapat mewakili atau representatif bagi populasi tersebut [6]. Penelitian ini menggunakan teknik pengambilan sampel dengan sensus. Teknik sensus merupakan teknik pengambilan sampel dimana
Jurnal Agrica Ekstensia

Vol. 15 No. 2 Tahun 2021

p-ISSN $\quad: 1978-5054$

e-ISSN semua anggota populasi dijadikan sampel [7]. Sampel penelitian ini adalah seluruh populasi yang ada, yaitu sebanyak 54 orang.

\section{Metode Pengumpulan Data}

Pengumpulan data pada penelitian ini dengan menggunakan sumber data primer dan data sekunder. Data primer diperoleh atau langsung dari lapangan, sedangkan data sekunder diperoleh dari sumber-sumber lain yang relevan. Data primer pada penelitian ini diperoleh dari responden, sedangkan data sekunder dari instansi terkait seperti BPP dan Dinas Pertanian dan Ketahanan Pangan Kabupaten Sragen. Metode pengumpulan data dilakukan dengan observasi, wawancara, studi pustaka, dan dokumentasi.

\section{Analisis Data}

Analisis data yang digunakan adalah dengan melakukan analisis statistik deskriptif, uji validitas dan reliabilitas serta analisis regresi linear berganda. Analisis statistik deskriptif menggunakan rumus lebar interval kelas. Uji validitas dan reliabilitas menggunakan uji statistik Cornbach Alpha dengan bantuan IBM SPSS 25. Analisis regresi linear berganda digunakan untuk mengetahui ada tidaknya pengaruh signifikan dua atau lebih variabel bebas terhadap variabel terikat [8]. Rumus analisis regresi linear berganda adalah sebagai berikut :

$$
\begin{aligned}
\mathrm{Y}=\mathrm{a} & +\mathrm{b}_{1} \mathrm{X}_{1} \\
& +\mathrm{b}_{2} \mathrm{X}_{2}+\mathrm{b}_{3} \mathrm{X}_{3}+\mathrm{b}_{4}+\mathrm{b}_{55}^{\mathrm{X}} \\
& +\varepsilon \ldots \operatorname{Pers}(1)
\end{aligned}
$$

Keterangan:

$\mathrm{Y}=$ Kinerja penyuluh pertanian

$\alpha=$ Konstanta

$\mathrm{b}=$ Koefisien regresi

$\varepsilon=$ Standar eror

$\mathrm{X}_{1}=$ Umur

$\mathrm{X}_{2}=$ Frekuensi Pelatihan Kerja

$\mathrm{X}_{3}=$ Masa Kerja

$\mathrm{X}_{4}=$ Jumlah Kelompok Tani Binaan

$\mathrm{X}_{5}=$ Ketersediaan Sarana dan Prasarana

HASIL DAN PEMBAHASAN

\section{Karakteristik Responden}

Karakteristik responden penyuluh pertanian di Kabupaten Sragen dapat dilihat pada Tabel 2. 
$\begin{array}{lll}\text { Info Artikel } & \text { Received } & : 13 \text { November } 2021 \\ & \text { Revised } & : 27 \text { Desember } 2021\end{array}$

Accepted :28 Desember 2021

Tabel 2. Karakteristik Responden Penyuluh Pertanian di Kabupaten Sragen Tahun 2021

\begin{tabular}{lrr}
\hline \multicolumn{1}{c}{ Karakteristik } & $\begin{array}{c}\text { Jumlah } \\
\text { (Orang) }\end{array}$ & $\begin{array}{c}\text { Persentase } \\
(\%)\end{array}$ \\
\hline 1. Jenis Kelamin & & \\
Laki-Laki & 39 & 72,20 \\
Perempuan & 15 & 27,80 \\
Jumlah & 54 & 100,00 \\
2. Golongan & & \\
II A & 6 & 11,11 \\
II B & 1 & 1,85 \\
III A & 11 & 20,37 \\
III B & 1 & 1,85 \\
III C & 8 & 14,81 \\
III D & 8 & 14,81 \\
IV A & 10 & 18,52 \\
IV B & 9 & 16,67 \\
Jumlah & 54 & 100,00 \\
\hline Sumber : Data Primer 2021 & &
\end{tabular}

Tabel 3. Kinerja Penyuluh Pertanian di Kabupaten Sragen

\begin{tabular}{clccc}
\hline No. & Kategori & Skor & $\begin{array}{c}\text { Persentase } \\
(\%)\end{array}$ \\
\hline 1 & Kurang Baik & $17,00-23,25$ & 13 & 24,07 \\
2 & Cukup Baik & $23,26-29,50$ & 21 & 38,89 \\
3 & Baik & $29,51-35,75$ & 13 & 24,07 \\
4 & Sangat Baik & $35,76-42,00$ & 7 & 12,96 \\
& Jumlah & & 54 & 100 \\
\hline
\end{tabular}

Sumber : Analisis Data Primer 2021

Berdasarkan Tabel 3 diketahui bahwa sebagian besar kinerja penyuluh pertanian di Kabupaten Sragen berada pada kategori cukup baik dengan jumlah penyuluh sebanyak 21 orang dari 54 orang responden. Kinerja penyuluh pertanian berada pada kategori cukup, yang artinya ada kegiatan penyuluh pertanian yang belum dilaksanakan secara maksimal tetapi beberapa kegiatan lain dilaksanakan sebaik mungkin dan petani melakukan rekomendasi yang diberikan [10]. Kinerja penyuluh pertanian terdiri atas tahap persiapan, pelaksanaan serta evaluasi dan pelaporan kegiatan, sehingga apabila ada tahap yang belum terlaksana secara maksimal dapat mempengaruhi hasil kinerja penyuluh. Kinerja penyuluh pertanian berada
Berdasarkan Tabel 2 dapat diketahui bahwa karakteristik jenis kelamin responden paling banyak adalah laki-laki sebanyak 39 orang dengan persentase $72,20 \%$. Karakteristik responden berdasarkan golongan/jabatannya dapat diketahui bahwa golongan paling banyak adalah golongan III A sebanyak 11 orang dengan persentase 20,37\%. Golongan/jabatan paling sedikit adalah golongan II B dan III B masingmasing sebanyak 1 orang dengan persentase $1,85 \%$.

\section{Kinerja Penyuluh Pertanian}

Kinerja penyuluh pertanian merupakan hasil kerja yang dicapai sesuai tugas dan tanggung jawab yang dilaksanakan secara efektif dan efisien [9]. Kinerja penyuluh pertanian dilihat melalui tahap persiapan, pelaksanaan serta evaluasi dan pelaporan program Kostratani. Hasil penilaian kinerja penyuluh pertanian di Kabupaten Sragen dapat dilihat pada Tabel 3. pada kategori cukup dikarenakan pada tahap evaluasi dan pelaporan memiliki hasil yang kurang baik, yaitu hanya melaksanakan kegiatan evaluasi sekitar 2 kali dalam satu periode keberjalanan program Kostratani.

\section{Faktor-Faktor yang Mempengaruhi Kinerja Penyuluh Pertanian}

Metode analisis regresi linear berganda pada penelitian ini dilakukan dengan menggunakan program IBM SPSS 25. Metode ini digunakan untuk mengetahui pengaruh antara variabel bebas terhadap variabel terikat. Hasil analisis regresi linear berganda dapat dilihat pada Tabel 4. 


\begin{tabular}{lllrr} 
& & & \multicolumn{2}{c}{ Jurnal Agrica Ekstensia } \\
\multirow{3}{*}{ Info Artikel } & Received & $: 13$ November 2021 & & Vol. 15 No. 2 Tahun 2021 \\
& Revised & $: 27$ Desember 2021 & p-ISSN & $: 1978-5054$ \\
& Accepted & $: 28$ Desember 2021 & e-ISSN & $: 2715-9493$ \\
\hline
\end{tabular}

Tabel 4. Hasil Analisis Regresi Linear Berganda

\begin{tabular}{lcc}
\hline \multicolumn{1}{c}{ Variabel } & $\mathrm{B}$ & Sig. \\
\hline (Constant) & 20,950 & 0,005 \\
Umur & 0,085 & 0,976 \\
Frekuensi Pelatihan Kerja & $\left.6,101^{*}\right)$ & 0,004 \\
Masa Kerja & 0,124 & 0,950 \\
Jumlah Kelompok Tani Binaan & $-1,782$ & 0,224 \\
Ketersediaan Sarana Prasarana & $-2,355$ & 0,104 \\
F hitung =2,332 & & 0,056 \\
$R$ Square $=0,195$ & \\
\hline Keterangan ${ }^{*}$ Signifikan & &
\end{tabular}

Koefisien regresi menunjukkan besarnya pengaruh variabel bebas terhadap variabel terikat. Berdasarkan hasil analisis regresi seperti yang disajikan pada Tabel 4, didapatkan persamaan regresi linear berganda sebagai berikut:

$$
\begin{array}{r}
Y=20,95+0,085 X_{1}+6,101 X_{2}+0,124 X_{3} \\
-1,782 x_{4}-2,355 X_{5} \ldots \text { Pers }
\end{array}
$$

Dari persamaan regresi linear berganda tersebut maka dapat disimpulkan bahwa:

- Nilai konstanta sebesar 20,950 yang dapat diartikan apabila semua variabel bebas (umur, frekuensi pelatihan kerja, masa kerja, jumlah kelompok tani binaan serta ketersediaan sarana dan prasarana) dianggap konstan, maka kinerja penyuluh pertanian sebesar 20,950;

- Pengaruh umur terhadap kinerja penyuluh adalah setiap adanya peningkatan satu satuan umur, maka akan meningkatan nilai kinerja penyuluh sebesar 0,085 dengan koefisiensi regresi positif;

- Pengaruh frekuensi pelatihan kerja terhadap kinerja penyuluh adalah setiap adanya peningkatan satu satuan frekuensi pelatihan, maka akan meningkatkan nilai kinerja penyuluh sebesar 6,101 dengan koefisiensi regresi bernilai positif;

- Pengaruh masa kerja terhadap kinerja penyuluh adalah setiap meningkatnya satu satuan masa kerja, maka akan meningkatkan nilai kinerja penyuluh sebesar 0,124 dengan koefisiensi regresi bernilai positif;

- Pengaruh jumlah kelompok tani binaan terhadap kinerja penyuluh adalah setiap adanya peningkatan satu satuan jumlah kelompok tani binaan, maka akan menurunkan nilai kinerja penyuluh sebesar
1,782 dengan koefisiensi regresi bernilai negatif;

- Pengaruh ketersediaan sarana dan prasarana terhadap kinerja penyuluh adalah setiap adanya peningkatan satu satuan ketersediaan sarana dan prasarana, maka akan menurunkan nilai kinerja penyuluh sebesar 2,355 dengan koefisiensi regresi bernilai negatif.

Untuk melihat pengaruh secara simultan faktor-faktor yang mempengaruhi kinerja penyuluh pertanian dapat diketahui melalui perhitungan nilai koefisien determinasi (KD) atau $\mathrm{R}^{2}$ yang dihasilkan. Koefisien Determinasi $\left(\mathrm{R}^{2}\right)$ digunakan untuk mengukur kemampuan model dalam menerangkan variasi variabel terikat. Hasil dari uji koefisien determinasi $\left(\mathrm{R}^{2}\right)$ dapat dilihat pada Tabel 4 diperoleh nilai $\mathrm{R}^{2}$ sebesar 0,195. Hal ini menunjukkan bahwa variasi variabel bebas (umur, frekuensi pelatihan kerja, masa kerja, jumlah kelompok tani binaan serta ketersediaan sarana dan prasarana) sebesar 19,5\% dapat menjelaskan variasi variabel terikat (kinerja penyuluh pertanian) dalam pelaksanaan program Kostratani, sedangkan sisanya sebesar $80,5 \%$ dipengaruhi oleh variabel bebas lain yang tidak diteliti.

Selanjutnya telah dilakukan Uji $F$ atau uji koefisien regresi secara serentak, yaitu untuk mengetahui pengaruh variabel bebas secara serentak terhadap variabel terikat, apakah pengaruhnya signifikan atau tidak. Hasil uji koefisiensi regresi serentak (Uji F) dari Tabel 4 menunjukkan bahwa nilai signifikansi $\mathrm{F}$ hitung sebesar 0,056 lebih besar daripada nilai signifikansi $(\alpha=0,05)$. Hal ini menunjukkan bahwa secara serentak variabel-variabel bebas (umur, frekuensi pelatihan kerja, masa kerja, jumlah kelompok tani binaan serta ketersediaan 
sarana dan prasarana) tidak memiliki pengaruh terhadap variabel terikat (kinerja penyuluh pertanian).

Untuk melihat pengaruh secara partial dari variabel bebas, telah dilakukan uji Parsial. Uji ini digunakan untuk menguji signifikansi pengaruh satu variabel independen secara individual dalam menerangkan variabel dependen [11]. Hasil uji parsial dilihat dari Tabel 4, maka masing-masing dapat dijelaskan sebagai berikut:

- Variabel bebas umur: nilai sig. sebesar 0,976 lebih besar daripada nilai signifikansi $(\alpha=$ $0,05)$, artinya tidak terdapat pengaruh nyata variabel bebas umur terhadap kinerja penyuluh pertanian dalam pelaksanaan program Kostratani. Hal ini didukung oleh pernyataan bahwa faktor-faktor yang mempengaruhi kinerja penyuluh pertanian tidak terdapat pengaruh nyata antara umur dengan kinerja penyuluh pertanian [12]. Hal ini karena penyuluh pada penelitian ini sebagian besar ada pada usia produktif;

- Variabel bebas frekuensi pelatihan kerja: nilai sig. sebesar 0,004 lebih kecil daripada nilai signifikansi $(\alpha=0,05)$, artinya terdapat pengaruh nyata variabel frekuensi pelatihan kerja terhadap kinerja penyuluh pertanian dalam pelaksanaan program Kostratani. Hal ini didukung oleh pernyataan bahwa variabel bebas pelatihan berpengaruh positif dan signifikan terhadap kinerja penyuluh pertanian lapangan [13]. Pelatihan dapat meningkatkan kemampuan dan keterampilan penyuluh, sehingga dapat meningkatkan produktivitas kinerja;

- Variabel bebas masa kerja: nilai sig. sebesar 0,950 lebih besar daripada nilai signifikansi $(\alpha=0,05)$, artinya tidak terdapat pengaruh nyata variabel bebas masa kerja terhadap kinerja penyuluh pertanian dalam pelaksanaan program Kostratani. Hal ini tidak sejalan dengan pernyataan bahwa semakin lama seseorang menggeluti satu jenis pekerjaan, maka semakin mudah bagi mereka mengetahui, memahami, dan menjalankan tugas dan tanggung jawabnya [14]. Hal ini terjadi karena kinerja dipengaruhi oleh faktor lainnya;

- Variabel bebas jumlah kelompok tani binaan: nilai sig. sebesar 0,224 lebih besar daripada nilai signifikansi $(\alpha=0,05)$, artinya tidak terdapat pengaruh nyata variabel bebas jumlah kelompok tani binaan terhadap kinerja penyuluh pertanian dalam

DOI: https://doi.org/10.55127/ae.v15i2.98 pelaksanaan program Kostratani. Hasil ini didukung oleh pernyataan bahwa jumlah kelompok tani tidak berpengaruh signifikan terhadap kinerja penyuluh pertanian [15]. Jumlah kelompok tani binaan setiap penyuluh sudah dibagi serata mungkin sesuai dengan jumlah penyuluh yang ada di setiap wilayah;

- Variabel bebas ketersediaan sarana dan prasarana: nilai sig. sebesar 0,104 lebih besar daripada nilai signifikansi $(\alpha=0,05)$, artinya tidak terdapat pengaruh nyata variabel bebas ketersediaan sarana dan prasarana terhadap kinerja penyuluh pertanian dalam pelaksanaan program Kostratani. Hal ini tidak sejalan dengan pernyataan bahwa ketersediaan sarana dan prasarana berhubungan dengan kinerja penyuluh pertanian [16]. Kurangnya kemampuan penguasaan teknologi informasi membuat sarana prasarana tidak berpengaruh nyata.

\section{KESIMPULAN}

1. Kinerja penyuluh pertanian dalam pelaksanaan program Kostratani di Kabupaten Sragen berada pada kategori cukup baik.

2. Faktor yang berpengaruh signifikan terhadap kinerja penyuluh pertanian dalam pelaksanaan program Kostratani di Kabupaten Sragen adalah frekuensi pelatihan kerja. Sedangkan faktor-faktor lain, yaitu: umur, masa kerja, jumlah kelompok tani binaan serta ketersediaan sarana dan prasarana tidak berpengaruh signifikan terhadap kinerja penyuluh pertanian dalam pelaksanaan program Kostratani di Kabupaten Sragen.

\section{DAFTAR PUSTAKA}

[1] Winarsih, Ahdah, Djaka M, Detia T Y. 2020. Peningkatan Kinerja melalui Program Kostratani di Balai Penyuluhan Pertanian (BPP) Prafi, Kabupaten Manokwari. Jurnal Triton Vol. 11 No. 2: 58-67.

[2] Purwanignsih NA, Fatchiya A, Mulyandari RS. 2018. Pemanfaatan Internet dalam Meningkatkan Kinerja Penyuluh Pertanian di Kabupaten Cianjur. Jurnal Penyuluhan Vol. 14 No. 1: 79-91. 
[3] Berlian M. 2014. Peran Penyuluh Pertanian Lapangan dan Partisipasi Petani dalam Porgram Feati serta Pengaruhnya terhadap Pendapatan Petani di Kecamatan Banyuasin Iii Kabupaten Banyuasin. Jurnal Matematika, Saint, dan Teknologi Vol. 15 No. 1: 52-62.

[4] Menteri Pertanian RI. 2013. Peratuan Menteri Pertanian No 91 Tahun 2013 tentang Pedoman Evaluasi Kinerja Penyuluh Pertanian. (Jakarta: Kementerian Pertanian Republik Indonesia).

[5] Siyoto, Sandu dan Effendi S. 2015. Dasar Metodologi Penelitian. (Yogyakarta: Literasi Media Publishing).

[6] Riyanto, Slamet dan Aglis A H. 2020. Metode Riset Penelitian Kuantitatif Penelitian di Bidang Manajemen, Teknik, Pendidikan dan Eksperimen. (Yogyakarta: Deepublish).

[7] Sugiyono. 2018. Metode Penelitian Kuantitatif. (Bandung: Alfabeta).

[8] Refiswal. 2018. Analisis Faktor-Faktor yang Mempengaruhi Kinerja Penyuluh Pertanian di Kabupaten Langkat. Jurnal Agrica Ekstensia Vol. 12 No. 2: 26-32.

[9] Mahyuddin, Thursina, Hanisah, Cut L R. 2018. Faktor-Faktor yang Mempengaruhi Kinerja Penyuluh Pertanian di Kabupaten Aceh Timur. Jurnal Agrisamudra Vol. 5 No.1: 2229.
[10] Surianti. 2017. Faktor-Faktor yang Mempengaruhi Kinerja Penyuluh Pertanian di Kabupaten Bantaeng. Skripsi Universitas Muhammadiyah Makassar.

[11] Ghozali, Imam. 2018. Aplikasi Analisis Multivariate dengan Program IBM SPSS 25. (Semarang: Badan Penerbit Universitas Diponegoro).

[12] Mahyuddin T, Hanisah, Rahmi CL. 2018. Faktopr-Faktor yang Mempengaruhi Kinerja Penyuluh Pertanian di Kabupaten Aceh Timur. Jurnal Penelitian Vol. 5 No. 1: 22-29.

[13] Mali, Celestino G T. 2012. Analisis Faktor-Faktor yang Mempengaruhi Kinerja Penyuluh Pertanian Lapangan (PPL) di Distrik Liquica, Timor Leste. Tesis UGM.

[14] Djamaluddin, Ahdar. 2014. System Kepercayaan dan Perubahan Social. (Yogyakarta: Trust Media).

[15] Lubis RA. 2014. Faktor-Faktor yang Mempengaruhi Kinerja Penyuluh Pertanian di Kabupaten Mandailing Natal. Tesis USU.

[16] Hasanuddin T, Viantamala B, Fitriyani A. 2019. Kinerja Penyuluh Pertanian dan Produktivitas Usahatani Jagung di Kecamatan Natar, Kabupaten Lampung Selatan. Jurnal of Extension and Development Vol. 1 No. 2: 134141. 